El apoyo a la guerra contra Paraguay en el debate público argentino (18651870)

María Victoria Baratta

páginas / año 11 - n 25 Enero-Abril / ISSN 1851-992X/ 2019

http://revistapaginas.unr.edu.ar/index.php/RevPaginas

\title{
El apoyo a la guerra contra Paraguay en el debate público argentino (1865-1870)
}

\author{
The support for the Paraguayan War in the public debate in \\ Argentina (1865-1870)
}

\author{
María Victoria Baratta \\ Instituto de Historia Argentina y Americana "Dr. Emilio Ravignani" \\ Universidad de Buenos Aires, \\ Consejo Nacional de Investigaciones Científicas y Técnicas (Argentina) \\ victoriabaratta@gmail.com
}

\begin{abstract}
Resumen
La Guerra del Paraguay (1865-1870) constituyó un elemento clave en el proceso de formación del estado nacional en Argentina. La resistencia a la guerra en Argentina ha sido ya estudiada en varios trabajos. Sin embargo, una guerra de escala inédita que duró cinco años nos interroga tanto por sus resistencias como por sus apoyos. Este artículo analiza el desarrollo y articulación de la defensa de la guerra contra Paraguay en el debate público argentino. Transita diferentes momentos del debate, del fervor inicial a las críticas a la alianza y la prolongación del conflicto. La permanencia de una visión negativa sobre el enemigo y su accionar durante toda la guerra fue un factor clave para explicar la participación argentina y la duración y consecuencias del conflicto armado.
\end{abstract}

\section{Palabras clave}

Guerra; Paraguay; Argentina; debate; apoyos

\begin{abstract}
The Paraguayan War (1865-1870) was a key element in the process of formation of the national state in Argentina. The resistance to the war within the country has already been studied in several works. However, in a war of unprecedented scale that lasted five years we should not only discuss the resistance but also the support. This article analyzes the development and articulation of the defense of the war against Paraguay in the Argentine public debate. It goes through different moments of the debate, from the initial fervor to the criticisms of the alliance and the prolongation of the conflict. The permanence of a negative view of the enemy and its actions throughout the war was a key factor in explaining Argentina's participation and the duration and consequences of the armed conflict.
\end{abstract}

\section{Keywords}

War; Paraguay; Argentina; debate; supports

Esta obra está sujeta a la Licencia Reconocimiento-NoComercial-CompartirIgual 4.0 Internacional de Creative Commons. http://creativecommons.org/licenses/by-nc-sa/4.0/

(cc) BY-NC-SA 
Los cuatro países que conformaron inicialmente el Mercosur se vieron envueltos en una guerra de enormes dimensiones hace más de 150 años. El Imperio de Brasil en alianza con la República Argentina y Uruguay se enfrentaron a Paraguay en una cruenta lucha que solo finalizó, luego de más de cinco años de conflicto, cuando se terminó con la vida del presidente paraguayo Francisco Solano López el $1^{\circ} \mathrm{de}$ marzo de 1870. Paraguay quedó devastado demográfica y económicamente y, además, fue ocupado durante siete años por los ejércitos de Brasil y de Argentina. La contienda constituyó un elemento clave en el proceso de formación del estado nacional en Argentina. La resistencia a la guerra en Argentina ha sido ya estudiada en varios trabajos (Alabart, 2015; Baratta, 2012 a, 2012 b; De La Fuente, 2008; entre otros). Los desbandes militares, los levantamientos en armas de las montoneras federales, los testimonios de deserción y el debate público dieron varias muestras de este fenómeno. Una revisión latinoamericanista de la historia de la guerra que comenzó a mediados del siglo pasado y que aún mantiene vigentes sus postulados básicos en el mercado editorial y el inconsciente colectivo -la corriente denominada como revisionismo histórico- ha llevado a absolutizar esta oposición y resistencia a la guerra (Pomer, 1986; Rosa, 1986; Galasso, 1975; entre otros). Este escrito no pretende negar ni silenciar esas resistencias ni mucho menos justificar o apoyar la guerra.

Una guerra que duró más de cinco años, y una ocupación que duró siete, nos interrogan tanto por sus resistencias como por sus apoyos. El máximo líder federal de Argentina Justo José de Urquiza prestó su apoyo a la contienda. Entre 24.000 y 30.000 soldados provenientes de todas las provincias participaron del ejército argentino en esa guerra, una cifra totalmente inédita hasta ese momento y en la historia posterior del país (Doratioto. 2002; Garavaglia y Fradkin, 2006). ¿Cómo pudo ser posible una guerra tan larga y sangrienta entre estos cuatro países americanos? ¿Quiénes fueron sus defensores en Argentina? ¿Cómo argumentaron su postura a lo largo de los diferentes momentos de la guerra? ¿Qué diferencias había entre quienes defendieron la guerra? Hay múltiples metodologías para acercarse a algunas respuestas, pero en este caso nos limitaremos a hacer un trabajo sobre el debate político público.

El objetivo de este artículo es reconstruir el debate público nacional en tanto la circulación de discursos políticos que esgrimieron una defensa de la guerra contra Paraguay en Argentina entre 1865 y 1870. La prensa (con sus editoriales, sus reproducciones de correspondencia y fuentes oficiales) ${ }^{1}$, los escritos publicados en esos años y las discusiones en el Congreso de la Nación son las fuentes elegidas. El discurso no es un ente deslindado de la historia social, sino que se nutre de ella y a su vez la moldea. Estudiaremos los procesos que se suceden dentro, pero con atención a lo que también pasa por fuera del lenguaje. En las fisuras y límites de esos discursos intentaremos interpretar también los silencios de los actores. Sabemos que las representaciones de los sectores populares tuvieron incidencia. Las

\footnotetext{
${ }^{1}$ Existen numerosos estudios sobre la prensa de la guerra en los otros países involucrados en el conflicto, para el caso argentino podemos citar entre otros a De Marco, 2003, Ramírez Braschi, 2004, Sujatovich, 2018, Navajas, 2009, Cucchi y Navajas, 2018 y Pérez, 2018.
} 


\section{El apoyo a la guerra contra Paraguay en el debate público argentino (1865- 1870)}

acotaciones metodológicas de nuestro estudio al análisis del discurso de las elites no las niegan, sino que las complementan. En definitiva, no se trata de desconocer o reemplazar perspectivas sino de sumar para una mejor comprensión de la guerra. En primer lugar, relevamos la prensa argentina y sus movimientos durante el inicio de la contienda: la lógica de defensa más extendida y encendida de la guerra guardó franca relación con los bríos de su comienzo, la firma del tratado aliado en Buenos Aires y el rol del presidente argentino como jefe de un ejército de tres países. Luego, abordamos la prensa al promediar la guerra, cuando las críticas a la contienda estaban extendidas, pero aun así presentaron sus límites. Analizamos finalmente el discurso de los principales líderes políticos, del Congreso y los escritos que circularon hacia el final.

\section{La ultrajante ofensa}

La decisión de Urquiza de dar su apoyo a Mitre en la guerra contra Paraguay es la clave inicial para comprender la dimensión inédita que adquirió el conflicto². Aun con los desbandes que sufrió su ejército la postura de no apoyo del líder federal a las revueltas montoneras y al propio Paraguay atraviesa toda la contienda. Un consenso entre las elites liberales y parte del federalismo o ex federalismo fue la base del inicio y desarrollo de la guerra desde Argentina. La prensa periódica fue el actor destacado del debate político de la época. Los debates parlamentarios, los escritos sueltos, las noticias del exterior, los editoriales, algunas fuentes oficiales, casi todo pasaba y se hacía resonante allí. Aunque una parte importante de la población era analfabeta los periódicos podían leerse a viva voz en algunos puntos de reunión. La prensa argentina de la época era una prensa partidaria que representaba las diferentes facciones en pugna de un estado recientemente unificado. Mitristas y autonomistas controlaban la mayor parte de los periódicos, aunque persistían muchos escritos de tendencia federal. Cada provincia tenía al menos un diario oficialista y luego fueron apareciendo los opositores (Sábato, 2012). En conjunto la prensa se mostró muy favorable a la entrada de la guerra de Argentina y la formación de la alianza hasta la derrota aliada en la batalla de Curupayty en 1866. Las excepciones fueron los periódicos de corte federal que apoyaron la invasión paraguaya en Corrientes y otros periódicos opositores con

\footnotetext{
2 "Mi estimado Presidente Me ha sorprendido de veras la noticia del ultraje inferido a nuestra patria por el Gobierno del Paraguay. V.E. ha hecho justicia a mis antecedentes y a la lealtad de mis declaraciones, señalándome un puesto a su lado. Todas las órdenes convenientes están expedidas para cumplir las de V.E., preparando los elementos necesarios para rechazar como se merece la ultrajante ofensa que bárbaramente nos han inferido. Ha llegado el momento en que las palabras deben hacer lugar a los hechos. Nos toca combatir juntos de nuevo bajo la bandera que reunió en Caseros a todos los argentinos. Me congratulo de ello, porque la felicidad de esta campaña fiada al tino y al patriotismo de V.E., mientras dará gloria a la República puede dar por resultado seguro extirpar del todo las disensiones políticas que antes habían dividido al país (...) Entretanto yo deseo el momento de estrechar a V.E. la mano, poniéndome personalmente a sus órdenes." Correspondencia Urquiza-Mitre, 19 de abril de 1865. AM.
} 


\title{
María Victoria Baratta
}

intervenciones breves, el más importante La América de Buenos Aires. En el caso de la prensa del litoral, el espacio-escenario de la contienda, las defensas explícitamente "paraguayistas" aparecieron ligadas al establecimiento del triunvirato en Corrientes, pero no cubrieron la totalidad de la opinión pública de la provincia (Ramírez Braschi, 2004). En el caso de Entre Ríos la prensa federal se mostró crítica ante la contienda, pero más como oposición al mitrismo y a la alianza con Brasil que por una defensa explícita a Paraguay (Baratta, 2011a).

El inicio del conflicto bélico encontró a prácticamente toda la prensa del país entusiasmada con la guerra. Para el periódico porteño mitrista La Nación Argentina dirigido por José María Gutiérrez era claro: a la guerra se iba en nombre de la nación argentina. La Tribuna de los hermanos Varela, de tendencia autonomista, enfrentado al mitrismo del presidente, se mostraba aún más efusivo con el inicio de la guerra, a la que consideraba la más popular de toda la historia y no cesó de repetir editoriales en ese sentido durante 1865:

\begin{abstract}
Podemos decirlo sin temor de ser desmentidos: jamás habrá emprendido el pueblo Argentino una guerra más popular, que aquella que acaba de retarlo la audacia del tirano López. Todo hombre de ideas grandes y generosas. Todo aquel que alguna vez haya sentido latir su corazón por una causa noble y todo el que ame la libertad y la democracia, sonríe de contento ante las esperanzas que esta guerra despierta. (...) El Presidente Mitre no deseaba esta guerra. López lo provoca a ella. En este caso el héroe de Pavón, toma nuevamente su espada y llamando en torno suyo a las legiones antes vencedoras, se apresta a la lucha con toda la fe que debe inspirarle el patriotismo de la nación. Adelante! Diga el General Mitre una palabra y el pueblo Argentino se pone de pie. Lo que quiere y desea, a lo que aspira, es a formar parte de la cruzada libertadora. Periódico La Tribuna, 23 de abril de 1865, HUNLP.
\end{abstract}

Al igual que La Nación Argentina, La Tribuna en un primer momento evitó mencionar que la guerra se hacía en alianza con el Imperio del Brasil. La estrategia era contraponer a un Paraguay bárbaro, despótico, tiránico en manos de un dictador a la Argentina civilizada, liberal y republicana que no hacía más que ir a liberar al pueblo paraguayo de su yugo. La prensa porteña compartía a grandes rasgos este entusiasmo inicial que se manifestaba también en las calles de Buenos Aires y en algunos círculos intelectuales. Los periódicos porteños más opositores al gobierno mitrista como El Pueblo, periódico fundado por Juan Chassaing y en el que participaría el futuro presidente del país Nicolás Avellaneda, no aportaron grandes críticas al inicio, se limitaron a desconfiar de la alianza, reprodujeron partes de los corresponsales de guerra y compartieron conceptos durante la guerra con los periódicos más afines al mitrismo. Si bien El Pueblo era crítico de la intervención de Bartolomé Mitre en la Banda Oriental, a la hora de la reacción ante la invasión 


\section{El apoyo a la guerra contra Paraguay en el debate público argentino (1865- 1870)}

paraguaya, se encontró apoyando su causa y tomando nota de los apoyos por fuera de Buenos Aires ${ }^{3}$.

El fervor discursivo que despertó en su inicio la guerra y la apelación sentimental y cultural a la identidad nacional por el comienzo de la misma, no se quedaron sólo en la prensa porteña. Pueden encontrarse prácticamente en todas las provincias en al menos uno de sus periódicos ${ }^{4}$. La mayoría de esos periódicos tenían sustento y relación con el estado nacional y aunque en general eran liberales, no todos eran necesariamente mitristas, muchos de ellos seguían la tendencia autonomista. Algunos replicaron editoriales de los diarios porteños como por ejemplo El Orden de la provincia Jujuy que además publicó la proclama del presidente Mitre que convocaba a la guerra. Por su parte, El Constitucional de la provincia de Mendoza, el 9 de mayo de 1865 publicó un editorial denominado: “La voz de la Patria!”, en el cual se denunciaba lo que se consideraba como un vil y traidor ataque por parte de Paraguay y llamaba defender los ideales de San Martín y Belgrano en defensa del honor nacional con la contundente frase "Ante todo somos Argentinos". Los ejemplos de la apelación a la nación, a la patria para el llamado de la guerra se repitieron en otras provincias como en este pasaje de la prensa en Córdoba o en Santiago del Estero:

\footnotetext{
3 "El pueblo de Buenos Aires ha visto con satisfacción a los dignos hijos de Tucumán. Ellos, después de una travesía de más de trescientas leguas en que han sufrido toda clase de privaciones vienen a tomar parte en la cruzada contra el déspota del Paraguay, que han ultrajado la honra argentina haciendo fuego sobre la bandera de Mayo". El Pueblo, 10 de octubre de 1865, HUNLP.

${ }^{4}$ Hemos relevado los siguientes periódicos: Correo del Domingo, Buenos Aires, 1865-1870, El Aguijón, Salta, 1865, El Centinela del Norte, Catamarca, 1867, El Comercio, Entre Ríos, 1867-1870, El Constitucional, 1864-1870 Mendoza, El Correo de Buenos Aires, Buenos Aires, 1864.El Correo del Norte, Salta, 1866, El Eco de Córdoba, Córdoba, 1866, El Eco de Corrientes, Corrientes, 1866-1868, El Eco de Entre Ríos, Entre Ríos, 1866, El Estudiante, Buenos Aires, 1866-1867, El Grillo, Buenos Aires, 1865, El Gualeguay, Entre Ríos, 1866-1868, El Imparcial, Corrientes, 1868, El Independiente, Corrientes, 1864-1865, El Liberal, Corrientes, 1868, El Liberal, Tucumán, 1864-1867, El Mosquito, Buenos Aires, 1864-1870, El Nacional, Buenos Aires, 1864-1868, El Nacionalista, Corrientes, 1866, El Norte, Santiago del Estero, 1864-1870, El Orden, Jujuy, 1863-1870, El Paraná, Entre Ríos, 1864-1867, El Patriota, Córdoba, 1867-1868, El Porvenir, Salta, 1868, El Porvenir, San Luis, 1864-1868, El Progreso, Córdoba, 1867, El Progreso, Corrientes, 1864-1865, El Progreso, Entre Ríos, 1866-1867, El Pueblo, Santa Fe, 1868-1869, El Pueblo, Buenos Aires, 1864-1867, El Pueblo, Santiago del Estero, 1863, El Republicano, Entre Ríos, 1865, El Tiempo, Santa Fe, 1865-1867, El Zonda, San Juan, 18641870, La Actualidad, Salta, 1864-1869, La América, Buenos Aires, 1866, La Capital, Rosario, Santa Fe, 1867-1870, La Discusión, Córdoba, 1865, La Época, Jujuy, 1868-1870, La Esperanza, Corrientes, 18641865, La Juventud, Tucumán, 1869, La Libertad, Catamarca, 1864, La Nación Argentina, Buenos Aires, 1864-1870, La Nación, Buenos Aires, 1870, La Opinión, Mendoza, 1870, La Paz, Santa Fe, 1868, La Prensa, Buenos Aires, 1869-1870, La Reforma, La Rioja, 1869, La Reforma, San Juan, 1866, La Regeneración, La Rioja, 1865-1867, La República, Buenos Aires, 1866, La Revista de Buenos Aires, Buenos Aires, 1864-1870, La Rioja, La Rioja, 1968, La Tribuna, Buenos Aires, 1864-1870, La Unión Americana, Buenos Aires, 1866-1867, La Unión, Catamarca, 1867, La Voz de Cuyo, San Juan, 18671870, La Voz de la Patria, Corrientes, 1868-1870, Las Provincias Unidas, Córdoba, 1868, Las Provincias, Córdoba, 1866, Revista Argentina, Buenos Aires, 1868-1870. A excepción de El Independiente en Corrientes, La América, La Unión Americana de Buenos Aires y El Pueblo de Santa Fe (son cerrados) El Porvenir, El Pueblo Entrerriano, El Eco de Entre Ríos y El Paraná ninguno se sale del discurso de apoyo a la entrada de la guerra contra Paraguay, incluso cuando las críticas a la alianza se habían generalizado. HBNMM y HUNLP.
} 
Somos, como el que más, enemigos de la guerra y la efusión de sangre, pero como argentinos ofendidos por la barbarie de un déspota, deseamos su completa destrucción, deplorando sinceramente el fanatismo o el temor arrastre al pueblo paraguayo a caer envuelto en la derrota junto con su Presidente. Por esto nos felicitamos de que la paz no haya tenido lugar, por esto nos felicitamos de que las operaciones continúen, pues la guerra se abrevia y creemos que concluya pronto". Periódico El Norte de Santiago del Estero, 8 de octubre de 1866. HUNLP.

El Zonda de la provincia de San Juan se mantuvo más expectante por la situación en Chile $^{5}$, aunque reprodujo partes del teatro de la guerra de la triple alianza. El apoyo a la guerra se manifestó con una puesta en primer plano de la identidad nacional por sobre las provinciales y la partidaria. La apelación al peligro para la región que supuestamente representaba el gobierno paraguayo fue invocada con recurrencia durante toda la contienda. Francisco Solano López era el jefe asesino, asimilable a la figura de Juan Manuel de Rosas (el mismo que le había denegado el reconocimiento de la independencia al Paraguay), era un "degollador". Apelar a la figura de Rosas era un recurso que podía relevarse efectivo en tres sentidos: en primer lugar, buscaba recordar la alianza con Brasil para Caseros para empatizar con la actual, en segundo lugar, buscaba un consenso con varios opositores al mitrismo, que también se declaraban antirrosistas. Por último se procuraba representar a López como un peligro para la región. Además de su malicia, para el mitrismo y sus aliados, el presidente paraguayo fue torpe, se equivocó en su lectura de la situación regional al describirla como un equilibrio y buscar su restitución.

Los paraguayos aparecían representados casi como animales sedientos de carne humana, sin piedad alguna, bárbaros, salvajes, violentos, villanos. El aislamiento del país, su falta de desarrollo económico, sus costumbres atrasadas lo convertían en un lugar más que peyorativo para la gran parte de la opinión pública argentina, no solo la mitrista. El Paraguay era un "enano" al lado de Brasil y Argentina y ahora era preciso demostrárselo por la fuerza a este déspota americano. Por oposición implícita o explícita al país vecino, la Argentina aparecía como un país civilizado, de ley, libertad y justicia. El discurso que buscó demonizar al presidente paraguayo, presentar su avance como un peligro para la nación y estigmatizar a su población fue una estrategia político-discursiva destinada a dotar de legitimidad a la guerra y a la necesidad de la alianza con el Brasil. El arraigo de una caracterización peyorativa pudo ser efectivo en tanto otras representaciones del Paraguay previas esgrimieron estos calificativos (Brezzo y Baratta, 2018). Las resignificaciones que aludían a la sangre, el degüello y los asesinatos representaron el grado de virulencia necesaria para la construcción de la imagen de un enemigo. Si bien durante el transcurso de la guerra se insistió con que la misma era que contra la tiranía de López y no contra su pueblo, lo cierto es que se encontraron algunas características negativas atribuidas

${ }^{5}$ Sobre la situación en Chile y las identidades puestas en juego durante el conflicto bélico con España existen estudios recientes como el de Cid, 2018. 


\section{El apoyo a la guerra contra Paraguay en el debate público argentino (1865- 1870)}

a los paraguayos como el fanatismo y la obediencia ciega por el terror. Los periódicos de varias provincias retomaron los partes de guerra en donde se referían a Francisco Solano López como "el tirano" aunque no con tanta persistencia como en Buenos Aires, quizás sí con más indiferencia. En Córdoba es donde más abordaron la cuestión en periódicos como El Progreso o Provincias Unidas. Periódicos de Jujuy, Santiago del Estero, Salta o Mendoza afines al mitrismo se hicieron eco de las noticias contra "el déspota".

El ensayo de José Manuel Estrada sobre Paraguay publicado en 1865 proporcionó una interesante oportunidad de profundizar en lo que la prensa se animaba a decir de manera no tan frecuente y clara. Estigmatizar no solo a Francisco Solano López sino a su pueblo como causa de su existencia. Un pueblo servil, atrasado, dócil era el caldo de cultivo perfecto para que se construyera el poder de un tirano ${ }^{6}$. El Paraguay era un caso anómalo en la América del siglo XIX, defensora de la libertad. La sociabilidad, la civilización no habían podido desarrollarse.

\section{A los argentinos de corazón}

La publicación del otrora secreto tratado de la triple alianza en mayo de 1866, la estrepitosa derrota militar en la batalla de Curupayty en septiembre de ese año, los problemas internos en Argentina y la dificultad de ejercer un mando efectivo sobre el ejército aliado alejaron a Mitre de su tarea como comandante en jefe del ejército aliado y dieron paso a las opiniones negativas de gran parte de la prensa. La Tribuna abandonó su euforia inicial y comenzó con las críticas a las estrategias militares, a la prolongación de la guerra, a los gastos y fundamentalmente a la alianza con Brasil. Esta tendencia pasó a ser la dominante en la prensa de todo el país. Una guerra civil se sumó a la internacional, las montoneras federales se levantaron en contra del gobierno de Mitre en 1866 y 1867, aunque fueron desconocidas en su legitimidad por todos los partidos políticos ${ }^{7}$ Mientras tanto la guerra contra Paraguay continuaba.

\footnotetext{
6 "El pueblo paraguayo es una masa sin vida, es una existencia atrofiada, una víctima que se resigna a todos los refinamientos de crueldad, con que el verdugo se complace en hacer sentir su mano. No se levanta una voz, no brota un pensamiento, no se escucha una palabra. El General López anuncia que tal día vino al mundo para la honra del despotismo, y las matronas y las doncellas de la Asunción danzan bajo la acción de un sol abrasador a la puerta de su Palacio, celebrando tan fausto acontecimiento (...) Hace cincuenta años que el pueblo paraguayo gime bajo los gobiernos personales. Ellos han muerto el nervio de la opinión pública, y su situación actual acongoja el alma. El comercio de la República está extinguido. Todas las producciones naturales del suelo, la madera, el tabaco, la yerba, están monopolizadas por el Gobierno. (...) El ruido del hacha de la civilización que engrandece las ciudades de sus vecinos y anula sus soledades, no tiene eco en el Paraguay." José Manuel Estrada. Ensayo histórico sobre la revolución de los comuneros del Paraguay y la guerra de 1865. Buenos Aires, 1865.

${ }^{7}$ Para un estudio del inicio del conflicto en Mendoza ver Bragoni, 2010. Un análisis de las resistencias a la guerra en todo el país puede encontrarse en Pomer, 1988 y sobre la situación específica de La Rioja y alrededores en De la Fuente, 2007.
} 
El Liberal de la provincia Tucumán daba cuenta de las resistencias que comenzaban a repetirse en La Rioja. Mientras tanto, en Catamarca los periódicos liberales también mostraban su preocupación por las crecientes disputas internas: "Lo que sucede en Catamarca en este momento, no es más que la consecuencia funesta de esas rencillas mezquinas que vienen distinguiendo a los partidos en la República Argentina, toda vez que se separan de aquella esfera que marean la Constitución y las leyes." (La Libertad, 6 de junio de 1866). En la provincia de Córdoba, El Eco atacaba la resistencia con su lema de "La Patria no está harta de sacrificios" y evitaba echar culpas a Mitre por Curupayty ${ }^{8}$.

Los pedidos de paz se repitieron en los periódicos que habían apoyado el inicio de las acciones bélicas. Y aunque este pedido se hizo presente en varios de sus discursos, la guerra contra el Paraguay continuó aún por tres años más. El Patriota de Córdoba, periódico político, jocoso y literario que defendió la candidatura presidencial de Sarmiento, se burlaba de las palabras de Mitre al comienzo de la contienda. El 2 de noviembre de 1867 publicaba un editorial titulado "La situación no está definida" que comenzaba con la frase "En tres días la situación estará definida" en clara alusión a los "En 24 horas en los cuarteles, en 15 días en campaña, en tres meses en Asunción" de aquellas palabras de Mitre. El Progreso de Córdoba por su parte, replicaba la disyuntiva de la prensa porteña opositora a la prolongación de la guerra. La mayoría de los periódicos pedían por la paz en el Paraguay, pero no a cualquier precio y además estaban en contra de las montoneras. Se quejaban de que la Guerra del Paraguay sacaba de la república argentina armas, hombres e ingresos que podrían estar combatiendo mejor a las revueltas de Cuyo. Para 1868 la rebelión de las montoneras estaba sofocada. Las elecciones presidenciales se encaminaban. El país volvía a su funcionamiento casi de rutina, puertas adentro. Sin embargo, el frente externo aún estaba encendido, aunque la suerte ya estaba decidida en favor de los aliados. La polémica más resonante se produjo entre La Nación Argentina y La Tribuna. Los periódicos otrora coincidentes en su postura bifurcaron cada vez más sus líneas de opinión en medio de la prolongación de la guerra y fundamentalmente, de las elecciones presidenciales que los encontraban defendiendo candidatos diferentes, mitristas y autonomistas. El periódico de los Varela había sido muy efusivo a la hora de exigir la alianza y la guerra al Paraguay. Pero a su vez, era cierto que los términos del tratado le habían sido desconocidos. Esta fue la obsesión de La Tribuna -y de la mayoría de los periódicos del país. La soberanía nacional ante Brasil podía verse cercenada y $L a$ Nación Argentina era defensora de esta deshonra. La oposición nacional a Brasil se imponía sobre la confrontación a Paraguay, ya en los opositores a la guerra como

\footnotetext{
8 "Hay quienes creen que las victorias del ejército aliado son derrotas y que sus antipatías van hasta poner en desacuerdo a los mismos que deben estar unidos hasta el fin de la campaña contra el tirano López. Tomen ellos nota de los siguientes párrafos de caras. Sus sueños fantásticos se desvanecen ante el patriotismo de los soldados de la libertad." Periódico El Eco de Córdoba, julio de 1866, HUNLP. "Es fuera de duda hoy que Tamandaré y Polidoro no han segundado el plan del Gral. en Jefe en su ataque a Curupaytí y que por esto ha fracasado una de las operaciones más importantes que haya emprendido el ejército aliado" Periódico El Eco de Córdoba, octubre de 1866, HUNLP.
} 


\section{El apoyo a la guerra contra Paraguay en el debate público argentino (1865- 1870)}

Alberdi y ahora en quienes la habían impulsado en su momento. En su obsesión de traición, los hermanos Varela le hablaban "a los argentinos de corazón” y señalaban un "fallido" del diario mitrista9. Teñir a La Nación Argentina con colores brasileños hablaba de una traición de la patria y también en este contexto de una salvación de un partido. Las acusaciones y las quejas por los gastos de la guerra de parte de $L a$ Tribuna se entremezclaban con croquis de campos de batalla como el de Humaitá y tributos en recuerdo y honor a Dominguito Sarmiento y Francisco Paz que habían fallecido en Curupayty. No existía una crítica profunda a la guerra en sí ni a su desencadenamiento y mucho menos una defensa al gobierno de Paraguay, aunque sí una lástima condescendiente por su pueblo. La crítica fundamental recaía en los efectos de su prolongación para el país y los términos del tratado con Brasil. En todo el territorio, los editoriales sobre la guerra menguaron para dejar paso al tema de las elecciones presidenciales.

\section{Un sello a nuestros labios}

En su último mensaje en la apertura de sesiones del Congreso de 1868 el presidente Mitre anunció que la guerra estaba llegando a su fin (aunque aún restaban dos años) y aseveró que la victoria estaba garantizada. No tuvo reparos en demostrar que para él no estaría finalizada hasta lograr las reivindicaciones territoriales que Argentina consideraba justas, aun cuando circulaban con fuerza críticas a las condiciones del tratado en la opinión pública. Vivificados por el desencanto creciente y por el pronto término de la gestión de Mitre, los legisladores argentinos por primera vez y a tres años de iniciada la contienda, empezaron a manifestar públicamente sus críticas a la guerra. El senador por Santa Fe, el liberal Nicasio Oroño, quien contribuyó a que su provincia se mantuviera en una relativa calma durante la contienda, presentó en junio de 1868 un Proyecto de negociaciones de paz ${ }^{10}$. En su exposición sobre la propuesta, apoyada también por los senadores Dávila y Navarro, opinaba:

\footnotetext{
9 “Hace muy pocos días La Nación Argentina traía estas textuales palabras: EL BRASIL DE ALIADO PUEDE CONVERTIRSE EN PRESIDENTE. Por honor de los argentinos pedimos al diario argentino la Nación que retirara esas palabras indignas de un hijo de estas Repúblicas. La Nación avergonzada ha exclamado al fin que ella no ha querido decir: Que el Brasil de aliado pueda convertirse en PRESIDENTE sino en Prescindente. La salida ha sido ridícula y algo gauchesca la verdad, pero al menos ya nos muestra que el Dr Elizalde está arrepentido de haber tan temprano, enseñado al pueblo su programa. Ya que la Nación retira esas palabras inocuas es preciso también que se declare arrepentida de haber escrito el mismo artículo estas otras aunque para ello busque otra palabra parecida a Prescindente: EL PARTIDO LIBERAL ESTA PERDIDO EN EL RIO DE LA PLATA SIN EL APOYO DEL BRASIL." Periódico La Tribuna, 18 de marzo de 1868, HUNLP.

10 "Proyecto de ley de Nicasio Oroño

El Senado y Cámara de Diputados de la Nación Argentina, resuelve:

Artículo 1 El Poder Ejecutivo Nacional procederá a la mayor brevedad posible a abrir negociaciones con los poderes aliados a objeto de poner término a la guerra exterior en que actualmente se halla empeñada la República Argentina, ya sea aceptando la mediación de una potencia amiga o entendiéndose directamente por medio de negociaciones con el Gobierno del Paraguay.

Art 2 Exonérase al Poder Ejecutivo de tomar los artículos adicionales al tratado de alianza de fecha 1 ro de Mayo de 1865, registrados en el protocolo o protocolos de la misma fecha, como base o condiciones a que se refiere el artículo anterior, limitándose estrictamente a exigir la satisfacción
} 
Cuando nuestro territorio fue invadido por fuerzas extranjeras sin previa declaración de guerra y sin ningún motivo racional justificado, era natural que el Gobierno Nacional, que los ciudadanos todos, movidos por un sentimiento de justa indignación, se lanzasen a repeler la agresión y a vengar el insulto inferido a la soberanía nacional y al honor de nuestro pabellón. (...) Llevamos tres años en esta lucha; los fines de la guerra se han alcanzado; la paz está pendiente de una solución que cada día se hace más remota y problemática; las fuerzas del país consagradas todas a la guerra, nos han obligado a distraer nuestros tesoros de su legítima y provechosa aplicación. Nuestra industria se ha paralizado, nuestros consumos se han aumentado, y disminuido notablemente nuestra producción. No podemos señor Presidente, ir más allá. El Congreso no puede dejar de tomar alguna medida o de dirigir sus miradas a la guerra que se sostiene en el exterior, porque en ella está cifrado el porvenir y la paz interior de la República." Nicasio Oroño, Sesión del 30 de junio de 1868, ANH

La crítica de Oroño a la prolongación era clara. La entrada a la guerra había sido en su opinión justa, pero su duración, inexplicable y perniciosa para el país. Vidas y recursos se fueron perdiendo a pasos agigantados. La contienda había implicado un esfuerzo nacional que ya no tenía sentido. Era hora de que el Congreso actuara. Sin embargo, el senador Elías contestó: "Yo creía, señor Presidente, que ni los honores de la discusión debía tener este proyecto." Seis meses después de presentado, el proyecto de Oroño fue desestimado. Aparecieron también en el parlamento durante 1868 proposiciones de mediación de paz de Estados Unidos, Chile y Bolivia, pero ninguna de ellas se concretó.

El real cimbronazo del poder legislativo en contra de la guerra llegó con el pedido de interpelación del Ministro de Guerra Juan Andrés Gelly y Obes. La interpelación se solicitaba para consultarle "cuántos hombres cuánta plata y cuánto tiempo necesita el Gobierno Nacional para dar concluida la guerra del Paraguay por medio de la victoria". Esto ocurrió el $1^{\circ}$ de junio de 1868 en la Cámara de Diputados con la voz del diputado por Buenos Aires, Manuel Quintana, ligado al autonomismo alsinista. Quintana no objetaba la causa del comienzo de la guerra y el entusiasmo inicial. La razón que daba origen al descontento eran los términos del tratado de la alianza que se habían hecho públicos dos años antes. El Ministro contestó que la paz interna estaba lograda pero había que ir por el enemigo en su propio territorio para que no volviese a invadir. La alianza se justificaba porque no quedaba alternativa para defenderse y por un posible frente de conflicto con el Brasil. El funcionario se defendió mencionando cifras de hombres en combate que solo produjeron protestas en el recinto. Las cifras que proporcionaba provocaron incredulidad e indignación. El presidente de la cámara manifestó que, si seguían los ruidos en la barra, se desalojaría y la sesión se podría volver secreta. Gelly y Obes prosiguió y quiso

conveniente al honor e intereses de los poderes aliados y respetando de igual modo la independencia del pueblo y Gobierno del Paraguay. Bs As, 30 de junio de 1868" Actas sesiones Congreso, ANH. 


\section{El apoyo a la guerra contra Paraguay en el debate público argentino (1865- 1870)}

demostrar que en ocho días de cólera se habían perdido más vidas que en dos años de guerra y agregó "Por lo demás, sucede que en toda guerra solo se sabe cuándo se tira el primer cañonazo; pero no se sabe cuándo se tirará el último."

Los diputados contestaron que el ejército había estado siempre desorganizado y la marina era nula. Algunos acusaban a Mitre de no haberse preparado mejor ante las amenazas, de haber perdido tiempo. Quintana prosiguió con su desconfianza en los números de víctimas y en su crítica a la alianza con el Brasil ${ }^{11}$. Quintana se indignó porque la Argentina no podía concluir la guerra con un rival tan menor para él12. En la sesión del 24 de julio de 1868 José Mármol defendió el derecho del Parlamento a conocer los asuntos exteriores de la República. En definitiva, todas las discusiones revelaban la poca injerencia parlamentaria en la guerra que llevaba adelante la república desde hacía tres años también por su propio desdén:

El Ministro Argentino en Río de Janeiro que se encuentra actualmente en esta capital, hizo al mismo tiempo que el Ministro Plenipotenciario de la República Oriental, la gestión de las justas exigencias de ambos Gobiernos aliados ante el Emperador del Brasil. El Emperador decretó terminantemente que estaba resuelto a no tratar con López ni con persona alguna de su familia, ni aún en el caso de una capitulación militar. Desde entonces, señor Presidente, pusimos un sello a nuestros labios y nos hicimos partidarios de la continuación indefinida de la guerra: desde entonces también desapareció en el Río de la Plata la política argentina y oriental, y quedó imperando la política brasilera únicamente. José Mármol, Cámara de Senadores, 30 de junio de 1868. ANH

El senador Mármol cerró esta impotente respuesta tardía del Congreso dejando en claro cuál era la mayor preocupación y mostrando los límites y responsabilidades del accionar del poder legislativo. El Congreso de la Nación emitió sus críticas a la guerra a más de tres años de su inicio, con un presidente que había sido el general

\footnotetext{
11 "La guerra señor, no ha venido a nuestro país por causa de la República Argentina; la guerra ha venido a la República Argentina a consecuencia de las promesas ciertas o falsas que el representante del Imperio del Brasil había hecho ante el Senado Brasilero. (...) Si hoy, según su declaración, no existen más de 10 o 12.000 hombres ¿qué se han hecho de los 16 o 20.000 soldados de que se componía el ejército? ¿Dónde están los 28.000 argentinos que la Memoria del Ministerio de la Guerra nos daba como existentes y armados? Nos ha dicho el Sr Ministro, para atenuar un tanto los estragos de la guerra, que en 8 o 10 días de cólera, han muerto más argentinos que en la guerra del Paraguay, pero ¿el Sr Ministro ignora que el cólera es uno de tantos azotes que la misma guerra del Paraguay nos ha traído? (Aplausos) Manuel Quintana, Cámara de Diputados, 1 ro de junio de 1868. ANH.

12 “(...) El Sr Ministro nos ha hablado de las riquezas del Paraguay, de lo repletas que estaban sus arcas y de lo bien armado de sus soldados. Las entradas del Paraguay no alcanzaban a un millón de patacones y es con entradas tan exiguas que no alcanzan a lo que produce en un año la Aduana de Buenos Aires que se puede sostener semejante tesis. ¿Qué era, Sr Presidente, por otra parte, el Ejército Paraguayo? (...) El armamento del Paraguay era tan inservible que cuando la toma de alguno de ellos tuvieron que abandonarlo. Pero sea de esto lo que fuere, sea que no hayan muerto sino 2000 argentinos, sin embargo que yo he leído que más de ese número cayó en Curupayty combate tan desdoroso para el que lo mandó (aplausos). Manuel Quintana, Cámara de Diputados, 1 ro de junio de 1868. ANH.
} 
en jefe del ejército aliado a punto de dejar su cargo y cuando la suerte de la contienda estaba casi decidida. La apelación a las ofensas inferidas al pueblo paraguayo y los aplausos se develarían entre insuficientes y dúplices. En los mismos discursos aplaudidos de Quintana se dejaba traslucir una visión condescendiente, paternalista y peyorativa porque se lo consideraba un rival menor en el que se estaba gastando demasiados recursos.

\section{Hasta el fin}

Mitre no logró imponer un sucesor. El candidato autonomista promovido por La Tribuna Domingo Faustino Sarmiento ganó las elecciones presidenciales en octubre de 1868. Aunque parte de las tropas emprendieron su regreso, Sarmiento continuó la guerra. La prensa se mantuvo en la misma tesitura y en 1869 publicó la polémica epistolar entre Bartolomé Mitre y el periodista uruguayo Juan Carlos Gómez que también abordó el tema de la cuestionada alianza con Brasil, pero no puso en duda la entrada en la guerra ni el carácter tiránico del gobierno de López. El fin de la guerra abrió una disputa entre los aliados que de alguna manera permitió, junto con la mediación norte americana, que el Paraguay continuara en el mapa. El ministro de relaciones exteriores Mariano Varela ya había hecho algunas reclamaciones sobre los arreglos territoriales al Imperio. Su intervención pasó a la historia como "la doctrina Varela". El 21 de diciembre de 1869 el ministro enunció la famosa frase "la victoria no da derechos a las naciones aliadas para declarar por sí, límites suyos los que el tratado señaló". El principal fundamento de la Doctrina Varela sostenía que, si el gobierno argentino había intervenido en la guerra de la Triple Alianza contra el gobierno de Francisco Solano López, lo había hecho por haber sido agredida por el dictador paraguayo y no por reclamos territoriales. En su discurso y accionar Varela demostraba más preocupación por la posibilidad de que Paraguay se convirtiera en un protectorado brasileño que por el destino del pueblo paraguayo. Bartolomé Mitre criticó la doctrina Varela y éste finalmente fue reemplazado en su puesto por Carlos Tejedor.

Hacia el fin de la contienda se editaron en Buenos Aires libros de dos británicos que trabajaron, vivieron en el Paraguay durante años y que estuvieron junto al ejército de López. En primer lugar, en 1869 apareció La Guerra del Paraguay del ingeniero George Thompson y en 1870 se editó Siete años de aventuras en el Paraguay de George Frederick Mastermann, boticario del ejército paraguayo. Estos dos personajes históricos estaban desencantados por el Mariscal y la mayor parte de sus críticas iban hacia él. Thompson consideraba a López "un monstruo sin paralelo" y era más condescendiente con el pueblo paraguayo que Masterman. Este pueblo que Thompson describió con benevolencia sufrió la ferocidad de su líder que hacia los últimos años de la guerra llevó adelante una política de juicios y fusilamientos a los 


\section{El apoyo a la guerra contra Paraguay en el debate público argentino (1865- 1870)}

sospechosos de traición, mujeres y niños huían atemorizados. López era un tirano que encontraba en hombres serviles su poder ${ }^{13}$.

Thompson y Masterman fueron seductores para los editores y periódicos porteños porque sintetizaron, legitimaron y ofrecieron una prueba en primera persona de las representaciones del Paraguay que se desplegaron durante toda la guerra. Masterman reconoció que no existía un odio de los argentinos a los paraguayos y que eso lo había demostrado la contienda. Las obras de Thompson y Masterman, junto con la publicación de los documentos públicos ${ }^{14}$, encontraron rápida acogida en las editoriales porteñas que buscaron difundir una idea legitimadora de una guerra ya muy impopular. Se trató de un refuerzo algo más efectivo de las estigmatizaciones que ya predominaban porque se basaban en relatos que provenían desde el mismo escenario de la guerra y en la pluma de ciudadanos de la "civilización" europea. El libro de Thompson fue reproducido en parte en varios periódicos del país, por ejemplo, en 1869 en el periódico La Opinión de Mendoza.

A pesar del hartazgo ante la guerra el ejército argentino continuó en el frente hasta el final, aunque en un número menor al de Brasil. Ambas fuerzas ocuparon Paraguay hasta 1876 y tuvieron peso en las disputas políticas internas. La presencia del ejército brasileño en Paraguay y sus negociaciones independientes despertaron el enojo en Argentina que había respetado a rajatabla un tratado que había hecho de la guerra un evento impopular. Un conflicto bélico con Brasil se insinuó, pero no llegó a considerarse seriamente por el estado de ambos países después de una guerra tan cruenta.

\section{A modo de conclusión}

El discurso público en Argentina se unificó con cierto fervor al comienzo de la guerra contra Paraguay y reflejó un consenso en las elites políticas liberales, mitristas y también autonomistas, y en parte del federalismo con Urquiza como líder. Este

\footnotetext{
13 "En cuanto a su patriotismo, la guerra misma prueba suficientemente que no conoce siquiera este sentimiento. Un tirano jamás encontraría una policía más dócil que los mismos hombres que han peleado por él con tanta abnegación. La inhumana crueldad con que ejecutaban sus órdenes puede ser atribuida en parte a la ferocidad natural y en parte al placer que hombres tratados con inusitada severidad, sienten en pisotear a los que les son superiores en nacimiento o fortuna". George Masterman. Siete años de aventuras en Paraguay. Buenos Aires, Imprenta Americana, 1870, p. 5. La otra obra es la de George Thompson. La Guerra del Paraguay. Buenos Aires, Imprenta Americana, 1869.

${ }^{14}$ Durante 1869 se publicó además en Buenos Aires por orden del Gobierno Nacional "Papeles del tirano del Paraguay tomados por los aliados en el asalto de 27 de diciembre de 1868", en el cual se repetían algunos de estos postulados peyorativos, Además ese mismo año se publicó la memoria del Ministro de Guerra Martín de Gainza al Congreso Nacional en el que se desplegaban las concepciones desplegadas durante toda la guerra sobre el gobierno paraguayo y se celebraba el accionar de la Legión Paraguaya. La Legión estuvo formada por un grupo de exiliados de los gobiernos de los López en Argentina y fue invocada, aunque no frecuentemente, como demostración de que la guerra era contra el gobierno y no contra el pueblo. La memoria del Ministro contenía además una carta de generales aliados "al pueblo paraguayo" en la que se les prometía la libertad como nación y se describía las acciones como "guerra al despótico gobierno del Paraguay, compasión al pueblo que gime bajo su férreo yugo", frase que se remarcaba con la tipografía.
} 


\section{María Victoria Baratta}

fervor se disipó con la prolongación inesperada del conflicto y la publicación del tratado que reflejaba una alianza con Brasil muy difícil de tolerar para ciertos sectores políticos. Argentina fue parte de la contienda durante los cinco años que duró y luego participó con su ejército de la ocupación de Paraguay durante siete años más. Durante esa ocupación impuso un feriado nacional, el estilo de la Constitución y ejerció hasta donde pudo su influencia en el gobierno provisorio.

A contramano de los enfoques revisionistas que han sostenido que la guerra fue muy impopular por una suerte de fervor latinoamericano "paraguayista", hemos encontrado un panorama muy diferente sobre las representaciones sobre Paraguay durante la guerra en Argentina. Una visión demonizante de su presidente y peyorativa de su pueblo más cierta indiferencia hacia su destino fueron las claves para explicar el porqué de la duración de la guerra para Argentina. Las resistencias se articularon mucho más en contra de la alianza con el Imperio del Brasil y contra la hegemonía porteña que sobre una defensa latinoamericana de Paraguay, tarea que casi exclusivamente llevó adelante Juan Bautista Alberdi desde el exilio.

La alianza con Brasil fue más impopular que hacer la guerra contra Paraguay. La guerra de la triple alianza fue la resistida, la guerra que se hizo contra Paraguay fue celebrada, luego justificada y más tarde criticada por su prolongación más que por su causa. La demonización del presidente paraguayo y la estigmatización del pueblo paraguayo estuvieron presentes en toda la contienda, en la prensa y en el discurso político y fueron parte también del discurso de los opositores a la alianza con Brasil. El consenso extendido sobre esta visión negativa de Paraguay atravesó a los principales espacios políticos liberales, mitristas y autonomistas y también a parte de ex federales y fue clave para que Argentina permaneciera en el conflicto hasta el final. La guerra fue defendida por un amplio sector, tolerada por otros y entre los opositores generó más indiferencia por el pueblo paraguayo que solidaridad y resistencia por su causa. Los costos económicos derivados del conflicto y las condiciones de la alianza con Brasil fueron los principales motivos de protesta y se volvieron explícitos en el Congreso recién tres años después del inicio de la contienda.

\section{Referencias}

AM Archivo Mitre

ANH Academia Nacional de la Historia

HBNMM Hemeroteca de la Biblioteca Nacional Mariano Moreno

HUNLP Hemeroteca Universidad Nacional de la Plata

\section{Bibliografía}




\section{El apoyo a la guerra contra Paraguay en el debate público argentino (1865- 1870)}

Alabart, Mónica (2015). "Resistencias a la Guerra del Paraguay e identidad federal: los desbandes de Basualdo y Toledo". En Alejandro Rabinovich e Ignacio Zubizarreta (coord.). La movilización militar y las formas de la política en el espacio rioplatense, 1810-1880. Foro del Programa Interuniversitario de Historia Política, http://historiapolitica.com/foros/movilizacion-militar/

Alonso, Paula comp. (2004). Construcciones impresas. Panfletos, diarios y revistas en la formación de los Estados nacionales en América Latina, 1820-1920. Buenos Aires: FCE.

Baratta, María Victoria (2012 a). "El litoral y la batalla de pluma: la identidad nacional argentina en los periódicos de Entre Ríos y Corrientes durante la Guerra del Paraguay (1864-1870)" en Folia Histórica del Nordeste. 21, 75-96.

Baratta, María Victoria (2012 b). "La identidad nacional durante la Guerra del Paraguay. Representaciones, lenguajes políticos y conceptos en el diario La Nación Argentina (1862-1870)" en Almanack, Guarulhos, 03, 82-98.

Bragoni, Beatriz (2010). “Cuyo después de Pavón. Consenso, rebelión y orden político, 1861-1874" en Beatriz Bragoni y Eduardo Míguez (coord.). Un nuevo orden político, Provincias y Estado Nacional, 1852-1880. Buenos Aires: Biblos.

Brezzo Liliana y Baratta, María Victoria (2018). "La imagen de la Argentina en el Paraguay" en Cavaleri, P. (dir) La Argentina vista por sus vecinos. Identidades y alteridades nacionales en América del Sur (pp. 143-206). Buenos Aires: Editorial Torre de Hércules.

Capdevila, Luc (2010). Una guerra total. Paraguay 1864-1870. Ensayo de Historia de Tiempo Presente. Asunción-Buenos Aires: CEADUC-Editorial SB.

Cid, Gabriel (2018). "En defensa de la "Patria Grande". Americanismo en la guerra en el Pacífico 1864-1866” en Mc Evoy, C. y Rabinovich, A. Tiempo de guerra. Estado, nación y conflicto armado en el Perú, siglos XVII-XIX. Lima: Instituto de Estudios Peruanos.

Cucchi, Laura y Navajas, María José (2018=. "El control de la prensa en la esfera nacional. Debates en el Congreso, la Justicia Federal y la Universidad de Buenos Aires (1862-1890)" en Quinto Sol, 22 (3), 1-21.

De la Fuente, Ariel (2007). Los hijos de Facundo. Caudillos y montoneras en la provincia de La Rioja durante el proceso de formación del Estado Nacional Argentino. Buenos Aires, Prometeo.

De Marco, Miguel Ángel (2003). Corresponsales en acción: crónicas de la Guerra del Paraguay, La Tribuna, 1865-1866. Buenos Aires: Librería Histórica. 


\section{María Victoria Baratta}

De Marco, Miguel Ángel (2003). La Guerra del Paraguay. Buenos Aires: Planeta.

Doratioto, Francisco (2002). Maldita Guerra. Nova Historia da Guerra do Paraguai. São Paulo: Companhia das letras.

Estrada, José Manuel (1865). "Ensayo histórico sobre la revolución de los comuneros del Paraguay y la guerra de 1865”. Buenos Aires, Imprenta de la Nación Argentina.

Galasso, Norberto (1975). Felipe Varela. Un caudillo latinoamericano. Buenos Aires, Ediciones Tiempo Latinoamericano.

Garavaglia Juan Carlos y Fradkin Raúl (2016). A 150 años de la Guerra de la Triple Alianza contra el Paraguay. Prometeo, Buenos Aires.

Goldman Noemí dir. (2008). Lenguaje y Revolución. Conceptos políticos clave en el Río de la Plata (1780-1850). Buenos Aires, Prometeo.

Halperín Donghi, Tulio (2004). Proyecto y construcción de una nación. Buenos Aires, Emecé.

Masterman, George (1870). Siete años de aventuras en Paraguay. Buenos Aires: Imprenta Americana.

Míguez, Eduardo (2018). Bartolomé Mitre, entre la nación y la historia. Buenos Aires: Edhasa.

Navajas, María José (2009). “Polémicas y conflictos en torno a la Guerra del Paraguay: los discursos en la prensa de Tucumán, Argentina (1864-1869)" en Nuevo Mundo, Mundos Nuevos, Coloquios, doi: 10.4000/nuevomundo.49313.

Papeles del tirano del Paraguay tomados por los aliados en el asalto de 27 de diciembre de 1868. Buenos Aires, Imprenta "Buenos Aires", 1869.

Pérez, Mariana (2015). "Poder político provincial y prensa federal en Entre Ríos: entre la subordinación y la autonomía” en Folia Histórica del Nordeste, 24, 35 - 58.

Pomer, León (1986). Cinco años de guerra civil en la Argentina (1865-1870). Buenos Aires, Amorrortu Editores.

Ramírez Braschi, Dardo (2004). La Guerra de la Triple Alianza a través de los periódicos correntinos. Corrientes: Moglia ediciones.

Rosa, José María (1986). La Guerra del Paraguay y las Montoneras argentinas. Buenos Aires, Hyspamerica.

Sábato, Hilda (2012). Historia de la Argentina. 1852-1890, Buenos Aires: Siglo XXI Editores. 
El apoyo a la guerra contra Paraguay en el debate público argentino (18651870)

Sujatovich, Luis (2018). "El Mosquito. La caricatura política en la presidencia de Bartolomé Mitre" en Question, 1(57), e29, https://doi.org/10.24215/16696581e029

Thompson, George (1869). La Guerra del Paraguay. Buenos Aires, Imprenta Americana.

Recibido: $16 / 02 / 2019$

Evaluado:20/03/2019

Versión Final: 15/04/2019 